\title{
Changes in expression of imprinted genes following treatment of human cancer cell lines with non-mutagenic or mutagenic carcinogens
}

\author{
TAKEO SHIBUI ${ }^{1,5}$, YUKARI HIGO ${ }^{2}$, TAKEO W. TSUTSUI ${ }^{2}$, MINORU UCHIDA $^{1}$, \\ MITSUO OSHIMURA $^{3}$, J. CARL BARRETT ${ }^{4,6}$ and TAKEKI TSUTSUI ${ }^{2}$ \\ ${ }^{1}$ Oral and Maxillofacial Surgery, The Nippon Dental University Hospital at Tokyo, Tokyo 102-8158; \\ ${ }^{2}$ Department of Pharmacology, The Nippon Dental University, School of Life Dentistry at Tokyo, Tokyo 102-8159; \\ ${ }^{3}$ Department of Molecular and Cellular Genetics School of Life Sciences, Tottori University, Tottori 680-0022, Japan; \\ ${ }^{4}$ Laboratory of Biosystems and Cancer, National Cancer Institute, National Institutes of Health, Bethesda, MD 20892-2440, USA
}

Received March 3, 2008; Accepted April 29, 2008

DOI: 10.3892/ijo_00000015

\begin{abstract}
It remains possible that chemicals that act by mutagenic mechanisms as well as chemicals that do not induce gene mutations may affect epigenetic gene expression. To test the possibility, we investigated the ability of both types of chemicals to alter the expression of five imprinted genes, PEG3, SNRPN, NDN, ZAC and H19, using two human colon cancer cell lines and a human breast cancer cell line.
\end{abstract}

Correspondence to: Dr Takeki Tsutsui, Department of Pharmacology, School of Life Dentistry at Tokyo, The Nippon Dental University, 1-9-20 Fujimi, Chiyoda-ku, Tokyo 102-8159, Japan

E-mail: takeki@tokyo.ndu.ac.jp

Present addresses: ${ }^{5}$ Department of Oral and Maxillofacial Surgery, Tokyo Dental College, 1-2-2 Masago, Mihama-ku, Chibashi, Chiba 261-8502 Japan; ${ }^{6}$ Novartis Institute for BioMedical Research Inc., 250 Maassachusetts Avenue, Suite 3A-203, Cambridge, MA 02139, USA

Abbreviations: 5-AzaC, 5-aza-2'-deoxycytidine; ChIP, chromatin immunoprecipitation; DES, diethylstilbestrol; DHFR, dihydrofolate reductase; DMSO, dimethylsulfoxide; DNMT, DNA methyltransferase; E1, functional ubiquitin-activating enzyme; $g p t$, bacterial xanthine guanine phosphoribosyltransferase; $h M L H 1$, human MutL homolog 1; hTERT, human telomerase catalytic subunit; H3-K4, histone $\mathrm{H} 3$ lysine 4; $\mathrm{H} 3-\mathrm{K} 9$, histone $\mathrm{H} 3$ lysine 9 ; $\mathrm{IC}_{50}, 50 \%$ inhibition of cell growth; LOI, loss of imprinting; MSP, methylation specific PCR; MMC, mitomycin $\mathrm{C} ; \mathrm{NiCl}_{2}$, nickel chloride hexahydrate; 4-NQO, 4-nitroquinoline 1-oxide; PBS (-), $\mathrm{Ca}^{2+}$ - and $\mathrm{MG}^{2+}$-free phosphate-buffered saline; PCR, polymerase chain reaction; RT$\mathrm{PCR}$, reverse transcriptase polymerase chain reaction; SAR, sodium arsenite

Key words: epigenetic modification, imprinted genes, chemical carcinogens, human cells
The expression of imprinted genes was changed by some nonmutagenic and mutagenic carcinogens independent of their mutagenic activity. The genes most commonly exhibiting the changes in expression were $S N R P N$ and PEG3. Alterations of the expression of $N D N$ and $Z A C$ were also observed in some conditions. Methylation-specific PCR and chromatin immunoprecipitation assays suggest the possibility that changes in the expression of SNRPN may be associated with DNA hypomethylation and histone acetylation of the promoters and euchromatinization of the heterochromatic domains of the promoters. Changes in expression of the imprinted genes, PEG3 and NDN, were also observed in cells immortalized by treatment of normal human fibroblasts with 4-nitroquinoline 1-oxide or aflatoxin $\mathrm{B}_{1}$. We previously demonstrated that expression of the cancer-related gene, INK $4 a$, in these immortal cells was lost via epigenetic mechanisms. The results prove that, in cancer cells, some mutagenic or nonmutagenic carcinogens can epigenetically influence the transcription levels of imprinted genes and also suggest the possibility that some chemical carcinogens may have epigenetic carcinogenic effects in human cells.

\section{Introduction}

Normal development involves tissue specific regulation of gene expression by epigenetic mechanisms. Certain genes are imprinted early in development and display allele specific gene expression depending on the parent of origin. The mechanisms of epigenetic regulation of expression of imprinted genes are complex involving both DNA methylation and chromatin modification. In imprinted genes such as H19, cytosine methylation of the $\mathrm{CpG}$ sequences in the promoter region is dependent on the gender of the parent from which the allele was inherited, and reflects allele-specific gene transcription (1). The expression of imprinted genes, which is suppressed by hypermethylation of promoter $\mathrm{CpG}$ sequences, can be restored by treatment with DNA methyltransferase inhibitors (2). Mechanisms of epigenetic regulation during development of non-imprinted genes are less well understood 
although changes in DNA methylation and chromatin structure are among the possibilities. The accumulation of epigenetic abnormalities in embryonic cells and embryonic stem cells during culture, especially the accumulation of changes in the expression of imprinted genes is potentially related with abnormal development in cloned and chimeric animals (3-5). The regulation of imprinted gene expression further highlights the role of epigenetic control of gene expression.

Epigenetic changes in gene expression are also important in malignant development (6-12). Changes of the normal pattern of parental origin-specific gene expression or loss of imprinting (LOI) are associated with various cancers. LOI is the most common molecular alteration in Wilms' tumors, an embryonal kidney cancer (11). LOI is also found commonly in most adult solid tumors, including colorectal, liver, and lung cancers, as well as in leukemia (11). Silencing of imprinted genes is also observed in many cancers (6).

The etiology of epigenetic changes in cancer is unknown. It is possible that chemical carcinogens may affect the expression of critical genes in the carcinogenesis process but methods to assess this potential activity of chemicals are lacking. Chemical carcinogens are often classified as mutagenic or non-mutagenic based on their ability to induce gene mutations in a variety of well-established assays (13). However, it remains possible that chemicals that act by mutagenic mechanisms as well as chemicals that do not induce gene mutations may affect epigenetic gene expression. To test this idea, we examined the ability of 6 non-mutagenic and 3 mutagenic carcinogens to affect the expression of 5 imprinted genes in three human cancer cell lines. The reasons for use of established cell lines are: i) human cancer cell lines have been utilized for studying the correlation between epigenetic modifications and expression of imprinted genes $(6,8-10,14)$; and ii) established cell lines have stable growth which is suitable for assessing the potential of chemicals to induce epigenetic modifications of imprinted genes with reproducible results. Our findings indicate that some chemical carcinogens of both classes can epigenetically influence the transcription levels of imprinted genes. In addition, we examined whether chemical carcinogens induced LOI in normal human fibroblasts to study the epigenetic carcinogenic effects of the chemicals.

\section{Materials and methods}

Cells and culture conditions. Human colorectal cancer cell lines (HTB-38 and CCL-247 cells), a human breast cancer cell line (HTB-22 cells), human immortal fibroblast cell lines [OUMS-24F cells (15) and LCS-AF.1-2 cells (16)], and a normal human fibroblast strain (WHE-7 cells) (17) were used in the present study. These cells were grown in Eagle's minimum essential medium containing $10 \%$ fetal bovine serum, $0.2 \mathrm{mM}$ serine, $0.1 \mathrm{mM}$ aspartic acid, $1.0 \mathrm{mM}$ pyruvate, and $0.22 \% \mathrm{NaHCO}_{3}$ at $37^{\circ} \mathrm{C}$ in a $5 \% \mathrm{CO}_{2}$ incubator. OUMS-24F cells were derived from a normal human fibroblast strain, OUMS-24 cells, which were immortalized by repeated treatments with 4-nitroquinoline 1-oxide (4NQO) (15). LCS-AF.1-2 cells were derived from a skin fibroblast strain, MDAH 087 cells, which were immortalized by aflatoxin $B_{1}$ in the presence of exogenous metabolic activation with rat liver post-mitochondrial supernatant $(16,17)$.

Chemicals. Non-mutagenic carcinogens: diethylstilbestrol (DES) (Sigma, St. Louis, MO), reserpine (Wako Pure Chemical, Osaka, Japan), and cyclosporin A (Wako Pure Chemical) were dissolved in dimethylsulfoxide (DMSO) (Sigma); sodium arsenite (SAR) (Sigma), and chlorpromazine hydrochloride (Wako Pure Chemical) were dissolved in $\mathrm{Ca}^{2+}$ and $\mathrm{Mg}^{2+}$-free phosphate-buffered saline (PBS (-), Nissui Pharmaceutical, Tokyo, Japan) and filter-sterilized; nickel chloride hexahydrate $\left(\mathrm{NiCl}_{2}\right)$ (Sigma) was dissolved in ethanol. Mutagenic carcinogens: 4-NQO (Wako Pure Chemical) and melphalan (Wako Pure Chemical) were dissolved in DMSO; mitomycin C (MMC) (Wako Pure Chemical) was dissolved in PBS (-) and filter-sterilized. The DNA methyltransferase inhibitor, 5-aza-2'-deoxycytidine (5-AzaC) (Sigma) used as a positive control for inducing LOI of imprinted genes, was dissolved in 50\% acetic acid. Ampicillin sodium (Wako Pure Chemical) and D-(-)-mannitol (Wako Pure Chemical), used as negative controls, were dissolved in PBS (-) and filtersterilized.

Determination of chemical concentrations. HTB-38 cells $\left(1 \times 10^{3}\right)$, CCL-247 cells $\left(2.5 \times 10^{2}\right)$, and HTB-22 cells $\left(1 \times 10^{3}\right)$ were plated on 96-well cell culture plates (Costar, Cambridge, MA) with $100 \mu$ l of medium and incubated overnight. Cells were treated with various concentrations of chemical carcinogens for 6 days during which medium was replenished every other day. The cells were washed once with PBS (-), and $125 \mu 1$ of a mixture of $25 \mu 1$ of CellTiter96 Aqueous One Solution (Promega, Madison, WI) and $100 \mu 1$ of culture medium were added to the plates, which were incubated for $1 \mathrm{~h}$ at $37^{\circ} \mathrm{C}$ in a $5 \% \mathrm{CO}_{2}$ incubator. The absorbance was recorded at $490 \mathrm{~nm}$ using a 96-well micro plate reader (Toso, Yamaguchi, Japan). The percentage of growth inhibition was determined from the absorbance of treatment group relative to the control $\mathrm{x} 100$.

Chemical treatment. HTB-38 cells $\left(4 \times 10^{5}\right)$, CCL-247 cells $\left(1 \times 10^{5}\right)$, and HTB-22 cells $\left(4 \times 10^{5}\right)$ were plated into $75-\mathrm{cm}^{2}$ flasks (Costar), incubated overnight and treated for 6 days with various chemical carcinogens at the concentrations that resulted in a $50 \%$ inhibition of cell growth $\left(\mathrm{IC}_{50}\right)$, because: i) treatment with 5 -AzaC at the concentrations of $\mathrm{IC}_{50}$ for 6 days induced changes in expression of imprinted genes in these cell lines; and ii) treatment of normal human cells with chemical carcinogens at the concentrations of around $\mathrm{IC}_{50}$ induced immortalization of the cells as well as changes in the expression of imprinted genes and tumor suppressor genes in the cells $(15,16,18$, Tsutsui, et al, Am Assoc Cancer Res Proc CD-ROM 47: abs. 2365, 2006). Media containing test chemicals were replenished every other day. Control cultures were incubated with media containing the same concentrations of solvents.

DNA and RNA isolation. Genomic DNA was extracted from cells with a DNA extract kit (DNA Extractor WB kit, Wako Pure Chemical). Total cellular RNAs were isolated from cells using the RNeasy Mini kit, (Qiagen, Hilden, Germany). Total 
Table I. PCR primer sequences and PCR conditions.

\begin{tabular}{|c|c|c|c|c|c|c|c|c|c|}
\hline \multirow{2}{*}{ Gene } & \multirow{2}{*}{ Primer } & \multirow{2}{*}{ Sequence $\left(5^{\prime}-3^{\prime}\right)$} & \multirow{2}{*}{$\begin{array}{l}\text { Product } \\
\text { size } \\
\text { (bp) }\end{array}$} & \multirow{2}{*}{$\begin{array}{c}\text { Initial } \\
\text { denature } \\
\left({ }^{\circ} \mathrm{C}\right)\end{array}$} & \multicolumn{4}{|c|}{ Amplification } & \multirow{2}{*}{$\begin{array}{c}\text { Final } \\
\text { extension } \\
\left({ }^{\circ} \mathrm{C}\right)\end{array}$} \\
\hline & & & & & $\begin{array}{c}\text { Denature } \\
\left({ }^{\circ} \mathrm{C} / \mathrm{sec}\right)\end{array}$ & $\begin{array}{c}\text { Annealing } \\
\left({ }^{\circ} \mathrm{C} / \mathrm{sec}\right)\end{array}$ & $\begin{array}{c}\text { Extension } \\
\left({ }^{\circ} \mathrm{C} / \mathrm{sec}\right)\end{array}$ & Cycles & \\
\hline \multirow[t]{2}{*}{ PEG3 } & $\mathrm{F}$ & ССТТССССТСGCATAАTAАCTA & 290 (gDNA, cDNA) & 95 & $95 / 30$ & $62 / 30$ & $72 / 30$ & 35 & 72 \\
\hline & $\mathrm{R}$ & тCTTCTGTCTGTCTCCTCTCCC & & & & & & & \\
\hline \multirow[t]{2}{*}{$S N R P N$} & $\mathrm{~F}$ & CTACTCTTTGAAGCTTCTGCC & 1119 (gDNA) & 95 & $95 / 30$ & $62 / 30$ & $72 / 50$ & 35 & 72 \\
\hline & $\mathrm{R}$ & TGAAGATTCGGCCATCTTGC & 218 (cDNA) & & & & & & \\
\hline \multirow[t]{2}{*}{$N D N$} & $\mathrm{~F}$ & GCCCGAATACGAGTTCTTTT & 540 (gDNA, cDNA) & 95 & $95 / 30$ & $62 / 30$ & $72 / 30$ & 35 & 72 \\
\hline & $\mathrm{R}$ & CACACATCATCAGTCCCATA & & & & & & & \\
\hline \multirow[t]{4}{*}{ ZAC } & GF & TGATTCTGAAGCGGTCAGGG & 368 (gDNA) & 95 & $95 / 30$ & $60 / 30$ & $72 / 60$ & 35 & 72 \\
\hline & GCR & CTGACCAAATGCTGTGCCAT & & & & & & & \\
\hline & $\mathrm{CF}$ & CCTGTCACTCAGTAGCCAA & 304 (cDNA) & 95 & $95 / 30$ & $60 / 30$ & $72 / 60$ & 25 & 72 \\
\hline & GCR & CTGACCAAATGCTGTGCCAT & & & & & & & \\
\hline \multirow[t]{2}{*}{ H19 } & $\mathrm{F}$ & TACAACCACTGCACTACCTG & 655 (gDNA) & 95 & $95 / 60$ & $95 / 180$ & $72 / 300$ & 34 & 72 \\
\hline & $\mathrm{R}$ & TGGAATGCTTGAAGGCTGCT & 575 (cDNA) & 95 & $95 / 60$ & $95 / 180$ & $72 / 300$ & 30 & 72 \\
\hline
\end{tabular}

F, forward; R, reverse; GF, forward for genomic DNA; GCR, reverse for genomic and complementary DNA; CF, forward for complementary DNA; gDNA, genomic DNA; cDNA, complementary DNA.

RNA $(2 \mu \mathrm{l})$ was reverse-transcribed with oligo (dT) primers by using the Ready-To-Go You-Prime First-Strand Beads (Amersham Bioscience, Piscataway, NJ) for first-strand cDNA synthesis according to the manufacturer's instructions.

DNA detection and RNA expression. Polymerase chain reaction (PCR) and reverse transcriptase polymerase chain reaction (RT-PCR) were performed in a reaction mixture (25 $\mu 1$ ) containing $1 \mu \mathrm{l}$ of DNA or RT reaction products, 0.025 units of Taq polymerase (AmpliTaq Gold, Applied Biosystems, Foster City, CA), $200 \mu \mathrm{M}$ dNTP, $15 \mathrm{mM}$ Tris$\mathrm{HCl}$ (pH 8.0), $50 \mathrm{mM} \mathrm{KCl}, 2.5 \mathrm{mM} \mathrm{MgCl}$, and 20 pmol of forward and reverse primers (Table I). The PCR products were subjected to a $2 \%$ agarose gel or $6 \%$ polyacrylamide gel (for the ZAC gene) electrophoresis. The gels were stained with SYBR-Green I (Biowhittaker Molecular Applications, Rockland, ME) and analyzed by a fluorescence imaging analyzer (Luminescent image analyzer, LAS-1000 plus, Fuji film, Tokyo, Japan). We measured restoration of expression of non-expressed genes. We also scored loss of expression of expressed genes. In the present study, we referred to both as LOI. For imprinted genes with conserved expression in cells following treatment with chemical carcinogens, we scored the results as 'not clear', because we did not know whether the expression was monoallelic or biallelic.

Methylation specific PCR (MSP) assay. HTB-38 cells were plated into $75-\mathrm{cm}^{2}$ flasks, incubated overnight and treated for 6 days with SAR or MMC at the concentrations of $\mathrm{IC}_{50}$. Genomic DNAs were treated with sodium bisulfite by using the CpGenome ${ }^{\mathrm{TM}}$ DNA modification kit (Intergen, Purchase, NY) according to the manufacturer's instructions. MSP assay was performed to examine the methylation status of the $\mathrm{CpG}$ islands within the SNRPN promoter region which is from $96 \mathrm{bp}$ upstream to $87 \mathrm{bp}$ downstream of the transcription start site for methylated allele and from $99 \mathrm{bp}$ upstream to $88 \mathrm{bp}$ downstream of the transcription start site for unmethylated allele. The primers used were methylated forward 5'-CAA ACA AAC ACG CCT ACG CGA CCG-3', methylated reverse 5'-GGT ATA GTT GAT TTT GTT CGT TTT ATC GC-3', unmethylated forward 5'-CAA CAA ACA AAC ACA CCT ACA CAA CCA-3', and unmethylated reverse 5'-TGG TAT AGT TGA TTT TGT TTG TTT TAT TGT-3' [sequence from GenBank (accession number MIM 182279)]. The PCR conditions were $95^{\circ} \mathrm{C}$ for $9 \mathrm{~min} ; 35$ cycles at $95^{\circ} \mathrm{C}$ for $1 \mathrm{~min}, 62^{\circ} \mathrm{C}$ or $69^{\circ} \mathrm{C}$ for unmethylated or methylated alleles, respectively, for $1 \mathrm{~min}$, and $72^{\circ} \mathrm{C}$ for $3 \mathrm{~min}$. The PCR products were purified using the MinElute PCR purification kit (Qiagen $\mathrm{GmbH}$ ), and then sequenced by Espec Co. (Tsukuba, Japan).

Chromatin immunoprecipitation (ChIP) assay. HTB-38 cells were plated, incubated overnight and treated for 6 days with various chemicals at the concentrations of $\mathrm{IC}_{50}$. The ChIP assay was performed with a ChIP assay kit (Upstate Biotechnology, Lake Placid, NY) with anti-dimethyl-Histone H3 (Lys 9), anti-dimethyl-Histone H3 (Lys 4), or anti-acetylHistone H4, as described previously (19). These antibodies were purchased from Upstate Biotechnology. Immunoprecipitated DNA was amplified with an advantage-GC genomic 


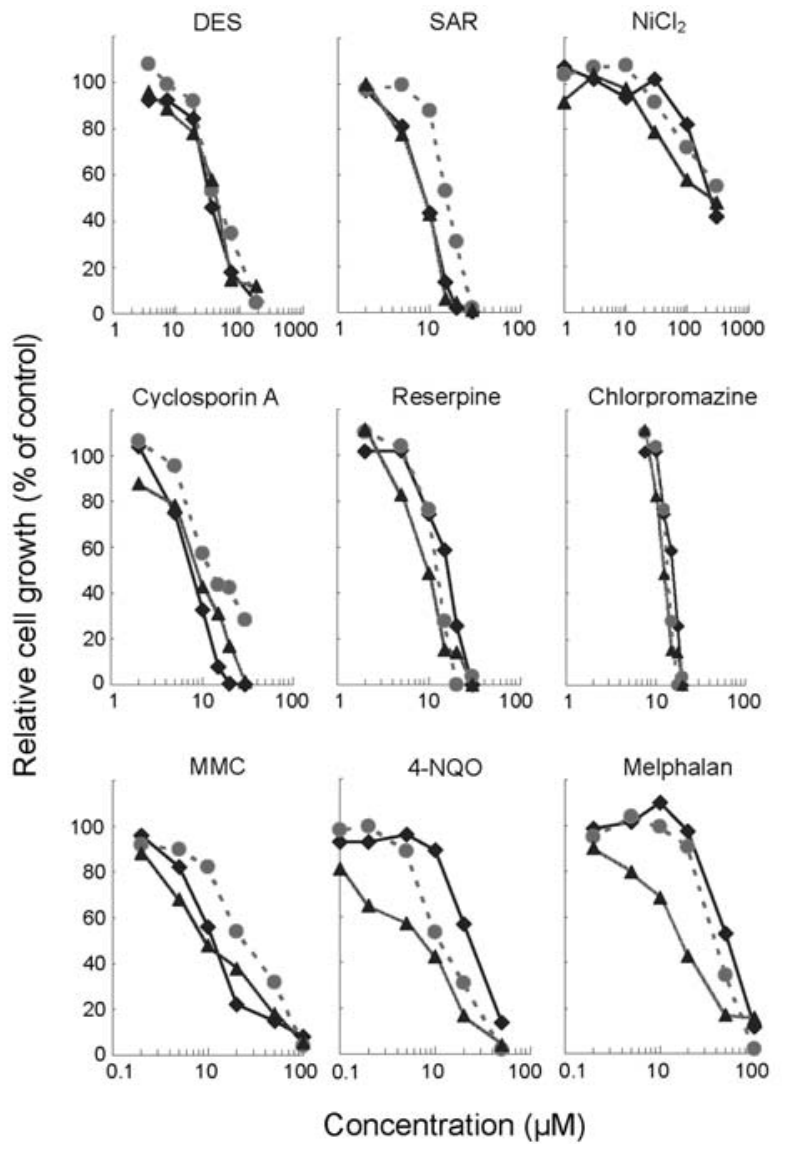

Figure 1. Effects of non-mutagenic or mutagenic carcinogens on the growth of human cancer cell lines. (A) Non-mutagenic carcinogens; (B) Mutagenic carcinogens. • HTB-38 cells; •, CCL-247 cells; ^, HTB-22 cells. DES, diethylstilbestrol; $\mathrm{SAR}$, sodium arsenite; $\mathrm{NiCl}_{2}$, nickel chloride hexahydrate; MMC, mitomycin C; 4-NQO, 4-nitroquinoline 1-oxide.

polymerase mix (Clontech, Palo Alto, CA). The primers used for amplification of the promoter region of $S N R P N$ which is from $54 \mathrm{bp}$ upstream to $120 \mathrm{bp}$ downstream of the transcription site (20) were sense, 5'-GAT GCT CAG GCG GGG ATG TGT GCG-3' and antisense, 5'-GCT CCC CAG GCT GTC TCT TGA GAG-3' (21). The PCR conditions were $94^{\circ} \mathrm{C}$ for $10 \mathrm{~min} ; 33$ cycles at $94^{\circ} \mathrm{C}$ for $30 \mathrm{sec}, 65^{\circ} \mathrm{C}$ for $30 \mathrm{sec}$, and $72^{\circ} \mathrm{C}$ for $30 \mathrm{sec}(21)$. CEN16 was used as the control PCR for DNA immunoprecipitated with methyl H3 Lys 9 (H3-K9) antibody and GAPDH was used as the control PCR for DNA immunoprecipitated with methyl H3 Lys 4 (H3-K4) and with acetyl H4. The primer sequences of CEN16 and $G A P D H$ and the PCR conditions were the same as those described by Xin et al (20) and Kumakura et al (19), respectively. The PCR products were subjected to a $2 \%$ agarose gel electrophoresis. The gels were stained and analyzed as described above.

\section{Results}

Determination of chemical concentrations for growth inhibition $\left(I C_{50}\right)$. Fig. 1 represents typical examples of growth inhibition curves after treatment of HTB-38, CCL-247, and HTB-22 cells with non-mutagenic or mutagenic carcinogens for 6 days. The $\mathrm{IC}_{50}$ values, calculated from the growth inhibition curves, are shown in Table II.

LOI by non-mutagenic carcinogens. The ability to induce LOI of 5 imprinted genes (PEG3, SNRPN, NDN, ZAC and H19) were examined after treatment of the 3 human cancer cell lines with 6 non-mutagenic carcinogens, DES, SAR, $\mathrm{NiCl}_{2}$, cyclosporin A, reserpine, and chlorpromazine and 2 non-carcinogens, ampicillin and mannitol. One representative data of 2 or 3 separate experiments with the same results is shown in Fig. 2A. In HTB-38 cells, DES, SAR, and $\mathrm{NiCl}_{2}$ induced the expressions of PEG3 and SNRPN which were not expressed in the control cells. These chemical carcinogens did not induce the expression of $N D N$, but $\mathrm{NiCl}_{2}$ induced the expression of ZAC. Chlorpromazine also induced the restoration of expression of $Z A C$ (data not shown). Although signals showing the expression of $H 19$ were weak, they were observed both in the control cells and cells treated with DES, SAR, or $\mathrm{NiCl}_{2}$, indicating that these 3 chemicals failed to silence the expression of H19. The other 2 non-mutagenic carcinogens failed to either induce or silence the expression of any of the 5 imprinted genes examined (data not shown). Treatment of HTB-38 cells with $5 \mu \mathrm{M}$ 5-AzaC for 6 days activated the expression of the 3 non-expressed imprinted genes, PEG3, SNRPN and NDN. In CCL-247 cells, DES, $\mathrm{SAR}$ and $\mathrm{NiCl}_{2}$ induced the expression of $S N R P N$, but failed to induce the expression of $N D N$. These 3 chemicals also failed to silence the expressions of ZAC and H19. The expression of $P E G 3$ was induced by SAR but not by DES nor $\mathrm{NiCl}_{2}$. The other 3 non-mutagenic carcinogens failed to either

Table II. The concentrations of non-mutagenic or mutagenic carcinogens that induced a $50 \%$ inhibition of cellular growth in human cancer cell lines.

\begin{tabular}{|c|c|c|c|c|c|c|c|c|c|}
\hline \multirow[b]{2}{*}{ Cell line } & \multicolumn{6}{|c|}{ Non-mutagenic carcinogens $(\mu \mathrm{M})$} & \multicolumn{3}{|c|}{ Mutagenic carcinogens $(\mu \mathrm{M})$} \\
\hline & DES & SAR & $\mathrm{NiCl}_{2}$ & Cyclosporin A & Reserpine & Chlorpromazine & MMC & 4-NQO & Melphalan \\
\hline HTB-38 & 37 & 10 & 300 & 10 & 15 & 10 & 1 & 5 & 5 \\
\hline CCL-247 & 37 & 30 & 300 & 10 & 15 & 13 & 2 & 2 & 5 \\
\hline HТB-22 & 37 & 10 & 300 & 10 & 10 & 11 & 1 & 1 & 2 \\
\hline
\end{tabular}

DES, diethylstilbestrol; $\mathrm{SAR}$, sodium arsenite; $\mathrm{NiCI}_{2}$, nickel chloride hexahydrate; MMC, mitomycin C; 4-NQO, 4-nitroquinoline 1-oxide. 
A

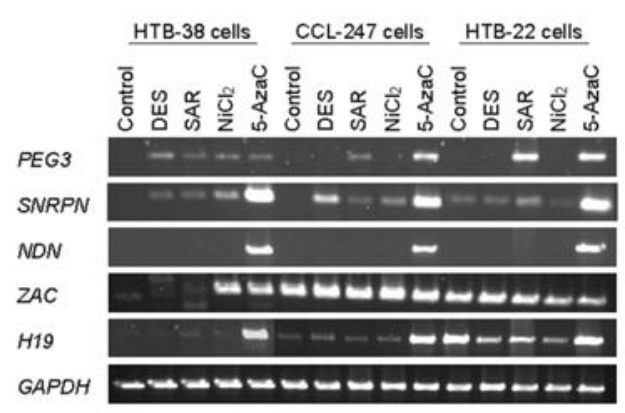

B

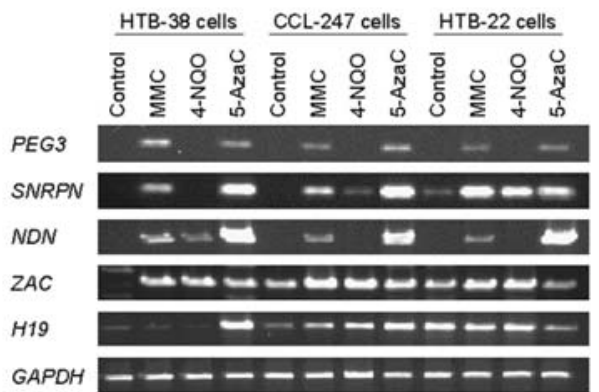

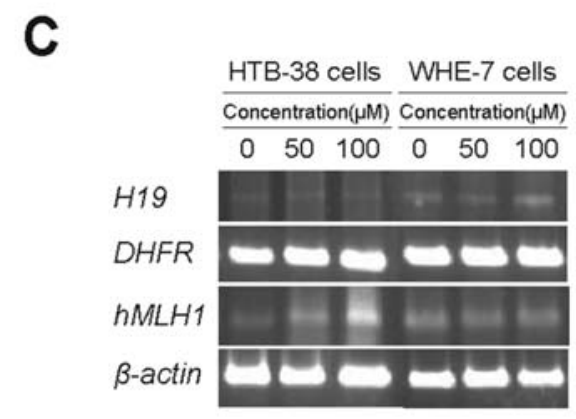

D

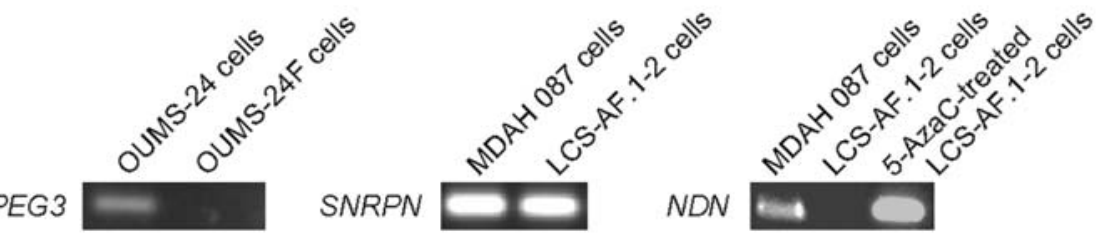

Figure 2. Expression of imprinted genes in human cells following treatment with non-mutagenic carcinogens or mutagenic carcinogens. (A) Expression of

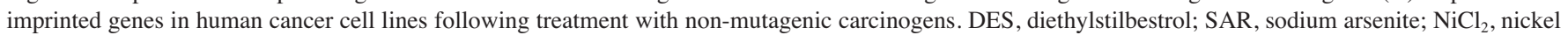
chloride hexahydrate; 5-AzaC, 5-aza-2'-deoxycytidine. (B) Expression of imprinted genes in human cancer cell lines following treatment with mutagenic carcinogens. MMC, mitomycin C; 4-NQO, 4-nitroquinoline 1-oxide; 5-AzaC, 5-aza-2'-deoxycytidine. The data presented (A and B) are representative of 1 of 2 or 3 separate experiments with the same results. (C) Expression of the imprinted gene, H19, and the non-imprinted genes, DHFR and $h M L H 1$, following treatment of HTB-38 cells or a normal human fibroblast strain, WHE-7 cells, with $50-100 \mu \mathrm{M} \mathrm{NiCl}_{2}$ for 3 weeks. B-actin was used as an internal control. (D) Expression of imprinted genes in human fibroblasts immortalized by treatment of normal fibroblasts with 4-NQO or aflatoxin $\mathrm{B}_{1}$. OUMS-24 cells were a normal human fibroblast strain. OUMS-24F cells were derived from OUMS-24 cells which were immortalized by repeated treatment with 4-NQO (15). MDAH 087 cells were a skin fibroblast strain. LCS-AF.1-2 cells were derived from MDAH 087 cells which were immortalized by aflatoxin B $_{1}$ in the presence of exogenous metabolic activation (16).

induce or silence the expressions of the 5 imprinted genes (data not shown). Treatment of CCL-247 cells with $0.1 \mu \mathrm{M}$ 5 -AzaC for 6 days induced the restoration of expression of the non-expressed imprinted genes, PEG3, SNRPN and NDN. In HTB-22 cells, the expression of PEG3 was induced by $\mathrm{SAR}$ but not by DES nor $\mathrm{NiCl}_{2}$. These 3 chemicals neither induced the expression of $N D N$ nor silenced the expression of SNRPN, ZAC and H19. The other 3 chemical carcinogens failed to either induce or silence the expression of any of the 5 imprinted genes in the 3 human cell lines (data not shown). Treatment of HTB-22 cells with $0.1 \mu \mathrm{M} 5$-AzaC for 6 days activated the expression of the 2 non-expressed imprinted genes, PEG3 and NDN. Ampicillin and mannitol, used as negative controls, neither induced nor silenced the expressions of the 5 imprinted genes examined (data not shown).
LOI by mutagenic carcinogens. We next examined the ability of 5 mutagenic carcinogens, MMC, 4-NQO, melphalan, cyclophosphamide, and phenacetin, to induce LOI of the 5 imprinted genes in the 3 human cancer cell lines. In HTB38 cells, MMC induced the expressions of PEG3, SNRPN, $N D N$ and $Z A C$ (Fig. 2B). 4-NQO elicited the expressions of $N D N$ and $Z A C$. However, neither MMC nor 4-NQO silenced the expression of H19. 4-NQO also failed to induce the expressions of PEG3 and SNRPN. In CCL-247 cells, MMC induced the expressions of PEG3, SNRPN and NDN. 4-NQO induced the expression of SNRPN. However, neither MMC nor 4-NQO silenced the expressions of ZAC and H19. 4-NQO also failed to induce the expressions of PEG3 and $N D N$. In HTB-22 cells, MMC induced the expressions of $P E G 3$ and $N D N$, but did not silence the expressions of the other 3 imprinted genes. 4-NQO failed to either induce 
Table III. Summary of changes in expression of imprinted genes in human cancer cell lines following treatment with nonmutagenic or mutagenic carcinogens.

\begin{tabular}{|c|c|c|c|c|c|c|c|c|c|c|c|c|c|c|c|c|c|c|c|c|c|c|c|c|c|c|c|c|}
\hline \multirow{3}{*}{ Chemical } & \multicolumn{19}{|c|}{ Non-mutagenic carcinogen } & \multirow{2}{*}{\multicolumn{3}{|c|}{$\begin{array}{c}\begin{array}{r}\text { Positive } \\
\text { control }\end{array} \\
\text { 5-AzaC } \\
\end{array}$}} & \multicolumn{6}{|c|}{ Negative control } \\
\hline & \multicolumn{3}{|c|}{ DES } & \multicolumn{3}{|c|}{ SAR } & \multicolumn{3}{|c|}{$\mathrm{NiCl}_{2}$} & \multicolumn{4}{|c|}{$\begin{array}{l}\text { Cyclo- } \\
\text { sporin A }\end{array}$} & \multicolumn{3}{|c|}{ Reserpine } & \multicolumn{3}{|c|}{$\begin{array}{c}\text { Chlor- } \\
\text { promazine }\end{array}$} & & & & \multicolumn{3}{|c|}{ Ampicillin } & \multicolumn{3}{|c|}{ Mannitol } \\
\hline & $\begin{array}{l}\infty \\
\stackrel{\infty}{0} \\
\Phi\end{array}$ & 竎 & స્ّ & $\begin{array}{l}\infty \\
\tilde{\rho} \\
\omega \\
\underline{\varphi}\end{array}$ & 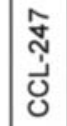 & 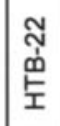 & 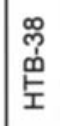 & 犬̃ & 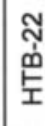 & 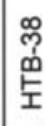 & $\begin{array}{l}\hat{7} \\
\frac{1}{0} \\
\text { U }\end{array}$ & g & & 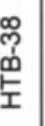 & 竎 & స્⿱ & 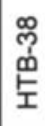 & 突 & 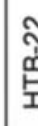 & $\begin{array}{l}\infty \\
\tilde{m} \\
\alpha \\
\underline{c}\end{array}$ & 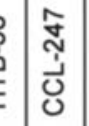 & 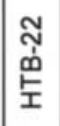 & 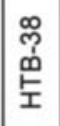 & $\begin{array}{l}\hat{\mathfrak{J}} \\
\stackrel{J}{U}\end{array}$ & 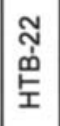 & 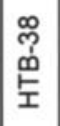 & 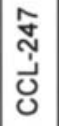 & สู \\
\hline & & & & & & & & & & & & & & & & & & & & & & & & & & & & \\
\hline & & & & & & & & & & & & & & & & & & & & & & & & & & & & \\
\hline
\end{tabular}

\begin{tabular}{|c|c|c|c|c|c|c|c|c|c|c|c|c|c|c|c|c|c|c|}
\hline \multirow{3}{*}{ Chemical } & \multicolumn{9}{|c|}{ Mutagenic carcinogen } & \multirow{2}{*}{\multicolumn{3}{|c|}{$\begin{array}{c}\text { Positive } \\
\text { control }\end{array}$}} & \multicolumn{6}{|c|}{ Negative control } \\
\hline & \multicolumn{3}{|c|}{ MMC } & \multicolumn{3}{|c|}{ 4-NQO } & \multicolumn{3}{|c|}{ Melphalan } & & & & \multicolumn{3}{|c|}{ Ampicillin } & \multicolumn{3}{|c|}{ Mannitol } \\
\hline & $\begin{array}{l}\stackrel{\infty}{9} \\
\stackrel{\omega}{\infty} \\
\text { 空 }\end{array}$ & 志 & $\begin{array}{l}\text { ฟิ } \\
\text { 奌 }\end{array}$ & $\begin{array}{l}\text { o } \\
\text { } \\
\text { 㟀 }\end{array}$ & 守 & $\begin{array}{l}\text { ส } \\
\text { 皇 } \\
\text { I }\end{array}$ & $\begin{array}{l}\text { o } \\
\text { 乩 } \\
\text { 贞 }\end{array}$ & 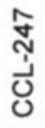 & $\begin{array}{l}\underset{\mathfrak{T}}{\mathfrak{T}} \\
\stackrel{\mathfrak{F}}{\vdash}\end{array}$ & 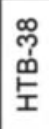 & 莳 & $\begin{array}{l}\text { ฟ } \\
\text { ஸ் } \\
\text { 兵 }\end{array}$ & $\begin{array}{l}\stackrel{\infty}{m^{\prime}} \\
\text { 皇 }\end{array}$ & ปั & $\begin{array}{l}\text { N } \\
\text { ஸ் } \\
\text { 兵 }\end{array}$ & $\begin{array}{l}\infty \\
\text { ஸे } \\
\infty \\
\text { 兵 }\end{array}$ & 莳 & 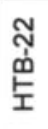 \\
\hline \begin{tabular}{|l} 
PEG 3 \\
SNRPN
\end{tabular} & & & & & & & & & & & & & & & & & & \\
\hline $\begin{array}{l}\text { NDN } \\
Z A C\end{array}$ & & & & & & & & & & & & & & & & & & \\
\hline H19 & & & & & & & & & & & & & & & & & & \\
\hline
\end{tabular}

Black boxes, restoration of expression of non-expressed imprinted genes; grey boxes, no restoration of expression of non-expressed imprinted genes; white boxes, not clear because no evidence to know whether the expression of expressed imprinted genes is monoallelic or biallelic. Des, diethylstilbestrol; SAR, sodium arsenite; $\mathrm{NICI}_{2}$, nickel chloride hexahydrate; 5-AzaC, 5-aza-2'-deoxycytidine; MMC, mitomycin C, 4-NQO, 4-nitroquinoline 1-oxyde.
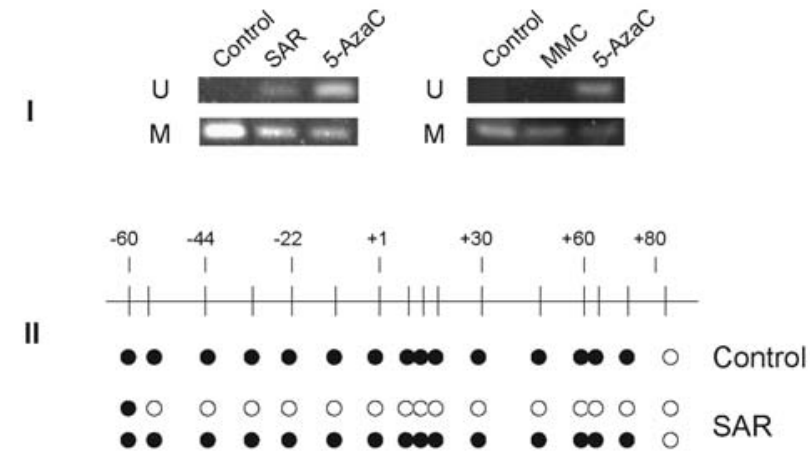

Figure 3. Methylation status of the SNRPN promoter in HTB-38 cells. I, methylation status of the $\mathrm{CpG}$ island in the promoter region of SNRPN in HTB-38 cells treated with SAR or MMC. Unmethylated (U) or methylated (M) DNA in the promoter region of SNRPN was detected by methylationspecific PCR analysis. II, methylation status of the $S N R P N$ promoter in HTB-38 cells treated with SAR as detected by DNA sequencing of the methylation-specific PCR products. The locations of the $\mathrm{CpG}$ sites ( $\circ$ and $\bullet$ ) are given in reference to the transcription start site. $\circ$, unmethylated $\mathrm{CpG}$ island; • methylated $\mathrm{CpG}$ island. SAR, sodium arsenite; 5-AzaC, 5-aza-2'deoxycytidine.

or silence the expression of any of the 5 imprinted genes. The other mutagenic carcinogen, melphalan, also failed to affect the expressions of the 5 imprinted genes in the 3 cell lines (data not shown). Treatment for 6 days of HTB-38, CCL-247, or HTB-22 cells with 5-AzaC at 5, 0.1, or $0.1 \mu \mathrm{M}$, respectively, induced the restoration of expression of all of the non-expressed imprinted genes in the 3 cell lines (Fig. 2B). All the results described above are summarized in Table III.

Only gene activation of non-expressed imprinted genes and no gene silencing of expressed imprinted genes were observed in the present study. Because the results may be due to short treatment time or limited concentration range that was studied and may also be due to the fact that only imprinted genes were studied, we examined whether treatment with lower concentrations $(50-100 \mu \mathrm{M})$ of $\mathrm{NiCl}_{2}$ for a longer time ( 3 weeks) induced changes in expression of the imprinted gene, H19, and the non-imprinted genes, DHFR (dihydrofolate reductase) and hMLH1 (human MutL homolog 1: one of human DNA mismatch repair genes), using HTB-38 cells and a normal human fibroblast strain, WHE-7 cells. Treatment with $50-100 \mu \mathrm{M} \mathrm{NiCl}_{2}$ for $2-3$ weeks has previously been shown to silence the gpt (bacterial xanthine guanine phosphoribosyltransferase) transgene via epigenetic mechanisms in G12 Chinese hamster cells in concentration- and treatment time-dependent manners (21). As shown in Fig. 2C, treatment of HTB-38 cells or WHE-7 cells with $50-100 \mu \mathrm{M} \mathrm{NiCl}_{2}$ for 3 weeks did not silence any of these genes.

LOI following treatment of normal human fibroblasts with chemical carcinogens. To examine whether LOI was induced by treatment of normal human fibroblasts with chemical 
A K9-methylated H3

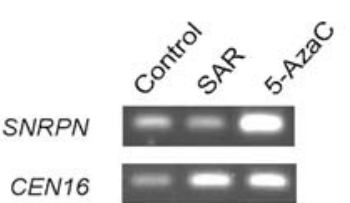

B K4-methylated H3

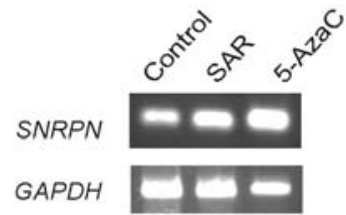

C Acetylated $\mathrm{H} 4$

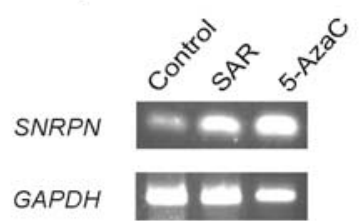

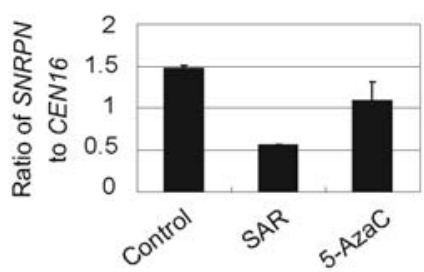
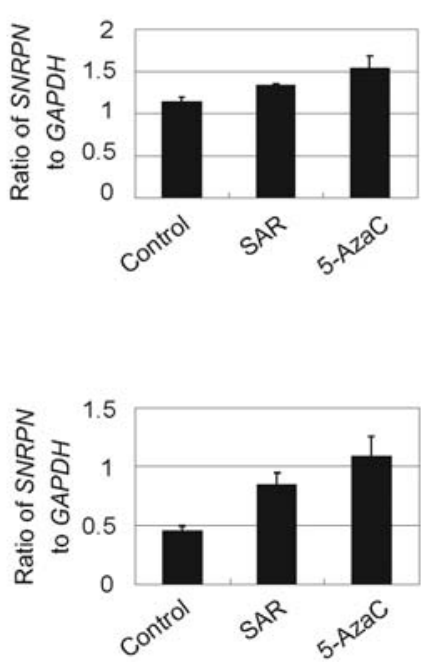

Figure 4. Methylation of histone H3 and acetylation of histone H4. (A) Methylation status of histone H3 lysine 9 (H3-K9) detected by ChIP assay in HTB-38 cells treated with SAR or 5-AzaC. ChIP PCR signals were quantified by densitometry with Software LabWorks version 4.0 (UVP, Upland, CA). CEN16 was used as the control PCR for DNA immunoprecipitated with dimethyl H3 Lys 9 antibody. (B) Methylation status of histone H3 lysine 4 (H3-K4) detected by ChIP assay in HTB-38 cells treated with SAR or 5-AzaC. GAPDH was used as the internal control. (C) Acetylation of histone H4 in HTB-38 cells treated with SAR or 5-AzaC. GAPDH was used as the internal control. Three separate experiments were carried out, and the same results were obtained. Bars denote SD. SAR, sodium arsenite; 5-AzaC, 5-aza-2'-deoxycytidine.

carcinogens, we compared imprinted gene expressions in the normal cells with those in their immortal cells induced by 4 NQO or aflatoxin $B_{1}$. Treatment of a human fibroblast strain, OUMS-24 cells, with 4-NQO induced loss of the expression of PEG3 in their immortal cells, OUMS-24F cells (Fig. 2D). Although the expression of SNRPN was conserved in human fibroblasts, LCS-AF.1-2 cells which were immortalized by treatment of a human fibroblast strain, MDAH 087 cells, with aflatoxin $B_{1}$ in the presence of exogenous metabolic activation, the expression of $N D N$ was lost in the cells. Expression of the NDN gene was reactivated by 5 -AzaC (Fig. 2D).

Methylation status of the CpG island in the SNRPN promoter region. To examine the association of imprinted gene expression induced by non-mutagenic or mutagenic carcinogens with demethylation of DNA, we studied the methylation status of the $\mathrm{CpG}$ island in the promoter region of the gene by an MSP assay. In these experiments, we analyzed the $\mathrm{CpG}$ islands in the promoter region of the $S N R P N$ gene in HTB-38 cells treated with SAR or MMC, because the promoter region was well characterized (22). The SNRPN CpG island was methylated in the control HTB-38 cells (Fig. 3). Weak and strong signals showing the unmethylated or methylated SNRPN CpG island, respectively, were observed in HTB-38 cells treated with SAR. Both signals exhibiting the unmethy- lated and methylated $\mathrm{CpG}$ islands were also observed in the cells treated with 5-AzaC. These results indicate that the CpG island of the SNRPN promoter in HTB-38 cells treated with SAR was partially methylated. The states of methylation of the CpG island were confirmed by the sequencing of MSP products where the $\mathrm{CpG}$ cytosines which lie from $60 \mathrm{bp}$ upstream to $87 \mathrm{bp}$ downstream of the transcription start site were largely methylated in the control HTB-38 cells and partially methylated in HTB-38 cells treated with SAR (Fig. 3). Conversely, HTB-38 cells treated with MMC had a signal only showing the methylated $\mathrm{CpG}$ island (Fig. 3).

ChIP assay at the SNRPN promoter. Because a difference in the methylation status of the SNRPN CpG island was found between the control HTB-38 cells and HTB-38 cells treated with SAR or 5-AzaC, we performed ChIP assay of the patterns of both methylations of histone $\mathrm{H} 3$ lysine 9 (H3-K9) and histone $\mathrm{H} 3$ lysine 4 (H3-K4) and acetylation of histone $\mathrm{H} 4$ to examine the possible involvement of chromatin states in the transcriptional regulation of the $S N R P N$ promoter. Methylation of H3-K4 and acetylation of histone H4 are well known to be associated with an open chromatin configuration such as that found at transcriptionally active promoters. In contrast, methylation of $\mathrm{H} 3-\mathrm{K} 9$ is a marker of condensed, inactive chromatin $(23,24)$. As shown in Fig. 4A, the SNRPN CpG island in HTB-38 cells treated with SAR or 5-AzaC had 
a lower or similar level, respectively, of H3-K9 methylation of the SNRPN CpG island compared with that in the control HTB-38 cells. Conversely, the SNRPN CpG island in HTB38 cells treated with SAR or 5-AzaC exhibited higher levels of H3-K4 methylation compared with that in the control cells (Fig. 4B). In addition, the levels of acetylation of histone $\mathrm{H} 4$ were greater in HTB-38 cells treated with SAR or 5-AzaC than in the control cells (Fig. 4C).

\section{Discussion}

Chromatin structure plays an important role in epigenetic gene regulation, and hypermethylation of $\mathrm{CpG}$ sequences in promoter regions silences gene transcription $(19,25,26)$. Furthermore, a methyl-CpG binding protein forms a complex with a histone deacetylase and modifies chromatin structure by deacetylating histone, which leads to transcriptional repression (27-29). The expression of imprinted genes can be influenced by a DNA methyltransferase inhibitor or a histone deacetylase inhibitor (30-33). The DNA methyltransferase inhibitor, 5-AzaC, activated the expression of all of the nonexpressed imprinted genes in the 3 human cancer cell lines used in the present study. Chemical carcinogens that affect the expression of imprinted genes have the potential to cause epigenetic modifications of cancer-related genes in human cells. Indeed, we demonstrated that human fibroblasts immortalized by either 4-NQO or aflatoxin $\mathrm{B}_{1}$ exhibited loss of expression of the imprinted genes, PEG3 and NDN. The gene expressions lost in the immortal cells were restored by treatment with 5-AzaC. In addition, we previously demonstrated that human fibroblasts immortalized by aflatoxin $\mathrm{B}_{1}$ exhibited gain of the imprinted gene, ZNF127 (15). These immortal cells also exhibited loss of $\mathrm{p} 16^{\mathrm{INK} 4 \mathrm{a}}$ protein expression by hypermethylation of $\mathrm{CpG}$ islands within the promoter region of INK4a (18). Furthermore, human fibroblasts immortalized by infection with a retrovirus vector encoding the human telomerase catalytic subunit ( $h T E R T)$ lost the expression of imprinted genes (PEG3, NDN and/or $M A G E-L 2)$ as well as INK4a by hypermethylation of the promoter (18).

Among the 9 chemicals examined, 4 non-mutagenic carcinogens, DES, SAR, $\mathrm{NiCl}_{2}$, and chlorpromazine, and 2 mutagenic carcinogens, MMC and 4-NQO, induced expression of PEG3, SNRPN, NDN, or ZAC in the 3 cell lines. The nonexpressed imprinted genes in these cancer cell lines were activated by these carcinogens independent of their mutagenic activity, suggesting that the mechanism of epigenetic effects is different from the mechanism for DNA mutation. The epigenetic effects of these carcinogens, particularly nonmutagenic carcinogens, may be involved in transformation of normal cells.

The genes activated by the chemicals varied among individual cell lines. One possibility for this heterogeneity may be differences in the ability of chemicals to inhibit DNA methyltransferase. 5-AzaC induced the restoration of expression of all of the non-expressed imprinted genes in the 3 cell lines. 5 -AzaC selectively degrades the maintenance DNA methyltransferase, DNMT1, by a proteasomal pathway and this process requires a functional ubiquitin-activating enzyme (E1) (34). Chemical carcinogens with higher activity for E1 may have the potential to induce a more pronounced degradation of DNMT1 and reactivate silenced genes. Only gene activation and no gene silencing were observed in the present study. This may be due to a difference of imprinted genes and a type of cells examined because some chemical carcinogens induced both loss and gain of expressions of various imprinted genes in human fibroblasts. Chen et al (21) reported that treatment with low concentrations of $\mathrm{NiCl}_{2}$ for ling times silenced the gpt transgene via epigenetic mechanisms in G12 Chinese hamster cells. Thus, we examined whether long-term treatment of HTB-38 cells or normal human fibroblasts with low concentrations of $\mathrm{NiCl}_{2}$ silenced the imprinted gene, H19, and the non-imprinted genes, DHFR and $h M L H 1$. However, treatment of HTB-38 cells or normal human fibroblasts with $50-100 \mu \mathrm{M} \mathrm{NiCl}_{2}$ for 3 weeks failed to silence both genes.

The imprinted genes most commonly influenced by the active chemical carcinogens were PEG3 and $S N R P N$. It is noteworthy that a high frequency of loss of expression of $P E G 3$ and NDN is observed in human cells immortalized either spontaneously or by viral oncogenes or chemical or physical carcinogens, suggesting that non-random imprinted genes may be affected by these carcinogens.

It has been reported that in paternally inherited imprinted genes, hypermethylation of $\mathrm{H} 3-\mathrm{K} 9$ and hypomethylation of $\mathrm{H} 3-\mathrm{K} 4$ of the chromatin containing the promoters are associated with gene silencing (20). The patterns of methylations of H3-K9 and $\mathrm{H} 3-\mathrm{K} 4$ and the acetylation status of $\mathrm{H} 3-\mathrm{K} 9$ and $\mathrm{H} 3-\mathrm{K} 14$ are linked to chromatin remodeling as well as transcriptional regulation $(35,36)$. Chemical carcinogens may influence posttranslational modification of histone proteins that could influence the expression of imprinted genes. In the present study, we demonstrated with MSP assays that restoration of expression of the non-expressed imprinted gene $S N R P N$ was associated with hypomethylation of the CpG island of the SNRPN promoter in SAR-treated cells but not in MMC-treated cells. Hypomethylation of H3-K9 and hypermethylation of $\mathrm{H} 3-\mathrm{K} 4$ methylation as well as increased levels of histone $\mathrm{H} 4$ acetylation of the chromatin containing the SNRPN promoter were observed in SAR-treated cells, indicating that SAR, but not MMC, can induce hypomethylation of the SNRPN promoter and euchromatinization of the heterochromatic domains of the promoter. These results suggest the possibility that changes in the $S N R P N$ expression induced by SAR may be associated with the chromatin structure-mediated regulation of SNRPN promoter. MSP and ChIP assays are being performed at the other promoters where chemical treatment resulted in a change in expression.

MMC is a direct-acting carcinogen and induces both intra- and interstrand DNA crosslinks that block key DNA metabolisms including DNA replication and transcription in MMC-treated cells (37). To our knowledge, there are no reports on the induction of altered expression of imprinted genes by MMC. Although the mechanisms remain to be clarified, MMC may induce expression of non-expressed imprinted genes by a mechanism other than hypomethylation of the $\mathrm{CpG}$ island in the promoter region of the genes.

Both non-mutagenic and mutagenic carcinogens, including DES, SAR, $\mathrm{NiCl}_{2}, \mathrm{MMC}$ and 4-NQO, affected the expression of the specific imprinted genes in human cancer cell lines. 
Hypomethylation in exon-4 of the c-fos, one of the key players in uterine carcinogenesis after estrogen stimulation, and elevated expression of c-fos are observed in mouse uterus upon neonatal exposure to DES, although the direct correlation between c-fos exon-4 hypomethylation and the elevation of its mRNA level remains unclear (38). Arsenic induces $\mathrm{CpG}$ island demethylation of tumor suppressor genes by inhibition of DNA methyltransferase and reactivates the silenced genes in human liver cancer cells (39). Arsenic also induces hypomethylation of proto-oncogenes leading to malignant transformation in mammalian cells $(40,41)$. Nickel ions are involved in both DNA methylation and histone deacetylation $(42,43)$. Although the mechanism by which nickel ions induced the restoration of expression of nonexpressed imprinted genes is unclear, Chen et al (21) have reported that nickel ions decrease the expression and activity of histone H3K9 specific methyltransferase G9a. Because the quinoline-based compound, designated S1027, causes selective degradation of DNMT1 in human cancer cells with minimal or no effects on DNMT3A and DNMT3B by a proteasomal pathway (Datta J, et al, Am Assoc Cancer Res Proc CD-ROM 48: abs. 4142, 2007), 4-NQO, one of the quinoline derivatives, can induce degradation of DNMT1 and re-express the non-expressed imprinted genes shown in the present study.

In summary, our findings indicate that, in cancer cells, some mutagenic or non-mutagenic carcinogens can epigenetically influence the transcription levels of imprinted genes. Because some chemical carcinogens affected the expression of not only imprinted genes but cancer-related genes in normal human cells, our results also suggest the possibility that some chemical carcinogens may have epigenetic carcinogenic effects in human cells.

\section{Acknowledgements}

This work was supported by a grant from the Long-range Research Initiative (LRI) in the Japan Chemical Industry Association (JCIA).

\section{References}

1. Murphy SK and Jirtle RL: Imprinted genes as potential genetic and epigenetic toxicologic targets. Environ Health Perspect 108: 5-11, 2000.

2. Hu JF, Vu TH and Hoffman AR: Promoter-specific modulation of insulin-like growth factor II genomic imprinting by inhibitors of DNA methylation. J Biol Chem 271: 18253-18262, 1996.

3. Dean W, Bowden L, Aitchison A, et al: Altered imprinted gene methylation and expression in completely ES cell-derived mouse fetuses: association with aberrant phenotypes. Development 125: 2273-2282, 1998

4. Humpherys D, Eggan K, Akutsu H, et al: Epigenetic instability in ES cells and cloned mice. Science 293: 95-97, 2001.

5. Rideout WM 3rd, Eggan K and Jaenisch R: Nuclear cloning and epigenetic reprogramming of the genome. Science 293: 1093-1098, 2001.

6. Tycko B: Epigenetic gene silencing in cancer. J Clin Invest 105: 401-407, 2000.

7. Jirtle RL, Sander M and Barrett JC: Genomic imprinting and environmental disease susceptibility. Environ Health Perspect 108: 271-278, 2000.

8. Malik K and Brown KW: Epigenetic gene deregulation in cancer. Br J Cancer 83: 1583-1588, 2000.

9. Schofield PN, Joyce JA, Lam WK, et al: Genomic imprinting and cancer; new paradigms in the genetics of neoplasia. Toxicol Lett 120: 151-160, 2001.
10. Plass C and Soloway PD: DNA methylation, imprinting and cancer. Eur J Hum Genet 10: 6-16, 2002.

11. Feinberg AP, Cui $\mathrm{H}$ and Ohlsson R: DNA methylation and genomic imprinting: insights from cancer into epigenetic mechanisms. Semin Cancer Biol 12: 389-398, 2002.

12. Feinberg AP, Oshimura M and Barrett JC: Epigenetic mechanisms in human disease. Cancer Res 62: 6784-6787, 2002.

13. Ashby J, De Serres FJ, Draper M, et al: Evaluation of short-term tests for carcinogenesis: Report of the International Programme on Chemical Safety's Collaborative Study on In Vitro Assays, Progress in mutation research. Vol 5. Elsevier Science Publishers, Amsterdam, 1985.

14. Maegawa S, Yoshioka H, Itaba N, et al: Epigenetic silencing of PEG3 gene expression in human glioma cell lines. Mol Carcinog 31: 1-9, 2001.

15. Bai L, Mihara K, Kondo Y, Honma M and Namba M: Immortalization of normal human fibroblasts by treatment with 4nitroquinoline 1-oxide. Int J Cancer 53: 451-456, 1993.

16. Tsutsui T, Fujino T, Kodama S, Tainsky MA, Boyd J and Barrett JC: Aflatoxin $\mathrm{B}_{1}$-induced immortalization of cultured skin fibroblasts from a patient with Li-Fraumeni syndrome. Carcinogenesis 16: 25-34, 1995.

17. Tsutsui TW, Inaba T, Fisher LW, Robey PG and Tsutsui T: In vitro chromosome aberration tests using human dental pulp cells to detect the carcinogenic potential of chemical agents. Odontology 94: 44-50, 2006

18. Tsutsui T, Kumakura S, Yamamoto A, et al: Association of $\mathrm{p} 16^{\mathrm{INK} 4 \mathrm{a}}$ and $\mathrm{pRb}$ inactivation with immortalization of human cells. Carcinogenesis 23: 2111-2117, 2002.

19. Kumakura S, Tsutsui TW, Yagisawa J, Barrett JC and Tsutsui T: Reversible conversion of immortal human cells from telomerasepositive to telomerase-negative cells. Cancer Res 65: 2778-2786, 2005.

20. Xin Z, Allis CD and Wagstaff J: Parent-specific complementary patterns of histone $\mathrm{H} 3$ lysine 9 and $\mathrm{H} 3$ lysine 4 methylation at the Prader-Willi syndrome imprinting center. Am J Hum Genet 69: 1389-1394, 2001

21. Chen H, Ke Q, Kluz T, Yan Y and Costa M: Nickel ions increase histone $\mathrm{H} 3$ lysine 9 dimethylation and induce transgene silencing. Mol Cell Biol 26: 3728-3737, 2006.

22. Saitoh S and Wada T: Parent-of-origin specific histone acetylation and reactivation of a key imprinted gene locus in Prader-Willi syndrome. Am J Hum Genet 66: 1958-1962, 2000.

23. Boggs BA, Cheung P, Heard E, Spector DL, Chinault AC and Allis CD: Differentially methylated forms of histone H3 show unique association patterns with inactive human $\mathrm{X}$ chromosomes. Nat Genet 30: 73-76, 2002.

24. Peters AH, Mermoud JE, O'Carroll D, et al: Histone H3 lysine 9 methylation is an epigenetic imprint of facultative heterochromatin. Nat Genet 30: 77-80, 2002.

25. Wolffe AP and Matzke MA: Epigenetics: regulation through repression. Science 286: 481-486, 1999.

26. Wolffe AP and Guschin D: Review: chromatin structural features and targets that regulate transcription. J Struct Biol 129: 102-122, 2000.

27. Bird AP and Wolffe AP: Methylation-induced repression-belts, braces and chromatin. Cell 99: 451-454, 1999.

28. Cheung P, Allis CD and Sassone-Corsi P: Signaling to chromatin through histone modifications. Cell 103: 263-271, 2000.

29. Turner BM: Histone acetylation and an epigenetic code. Bioassays 22: 836-845, 2000.

30. Issa JP, Vertino PM, Boehm CD, Newsham IF and Baylin SB: Switch from monoallelic to biallelic human IGF2 promoter methylation during aging and carcinogenesis. Proc Natl Acad Sci USA 93: 11757-11762, 1996.

31. Riesewijk AM, Hu L, Schulz U, et al: Monoallelic expression of human PEG1/MEST is paralleled by parent-specific methylation in fetuses. Genomics 42: 236-244, 1997.

32. Yu Y, Xu F, Peng H, et al: NOEY2 (ARHI), an imprinted putative tumor suppressor gene in ovarian and breast carcinomas. Proc Natl Acad Sci USA 96: 214-219, 1999.

33. El Kharroubi A, Piras G and Stewart CL: DNA demethylation reactivates a subset of imprinted genes in uniparental mouse embryonic fibroblasts. J Biol Chem 276: 8674-8680, 2001.

34. Ghoshal K, Datta J, Majumder S, et al: 5-Aza-deoxycytidine induces selective degradation of DNA methyltransferase 1 by a proteasomal pathway that requires the KEN box, bromo-adjacent homology domain, and nuclear localization signal. Mol Cell Biol 25: 4727-2741, 2005. 
35. Jones PL, Veenstra GJ, Wade PA, et al: Methylated DNA and $\mathrm{MeCP} 2$ recruit histone deacetylase to repress transcription. Nat Genet 19: 187-191, 1998.

36. Nakayama J, Rice JC, Strahl BD, Allis CD and Grewal SI: Role of histone H3 lysine 9 methylation in epigenetic control of heterochromatin assembly. Science 292: 110-113, 2001.

37. Poll EH, Arwert F, Kortbeek HT and Eriksson AW: Fanconi anaemia cells are not uniformly deficient in unhooking of DNA interstrand crosslinks, induced by mitomycin $\mathrm{C}$ or 8-methoxypsoralen plus UVA. Hum Genet 68: 228-234, 1984

38. Li S, Hansman R, Newbold R, Davis B, McLachlan JA and Barrett JC: Neonatal diethylstilbestrol exposure induces persistent elevation of $\mathrm{c}$-fos expression and hypomethylation in its exon-4 in mouse uterus. Mol Carcinog 38: 78-84, 2003.

39. Cui X, Wakai T, Shirai Y, Yokoyama N, Hatakeyama K and Hirano S: Arsenic trioxide inhibits DNA methyltransferase and restores methylation-silenced genes in human liver cancer cells. Hum Pathol 37: 298-311, 2006.
40. Zhao CQ, Young MR, Diwan BA, Coogan TP and Waalkes MP Association of arsenic-induced malignant transformation with DNA hypomethylation and aberrant gene expression. Proc Natl Acad Sci USA 94: 10907-10912, 1997.

41. Takahashi M, Barrett JC and Tsutsui T: Transformation by inorganic arsenic compounds of normal Syrian hamster embryo cells into a neoplastic state in which they become anchorageindependent and cause tumors in newborn hamsters. Int $\mathbf{J}$ Cancer 99: 629-634, 2002.

42. Costa M, Sutherland JE, Peng W, Salnikow K, Broday L and Kluz T: Molecular biology of nickel carcinogenesis. Mol Cell Biochem 222: 205-211, 2001.

43. Broday L, Peng W, Kuo MH, Salnikow K, Zoroddu M and Costa M: Nickel compounds are novel inhibitors of histone $\mathrm{H} 4$ acetylation. Cancer Res 60: 238-241, 2000. 